\title{
Voiding Dysfunction in Mice With Experimental Autoimmune Encephalomyelitis: A Multiple Sclerosis-Like Disease
}

\author{
Lucie Even ${ }^{\mathrm{a}, \mathrm{b}, \mathrm{e}}$, Ourdia Bouali ${ }^{\mathrm{a}, \mathrm{b}, \mathrm{c}}$, Mathieu Roumiguie ${ }^{\mathrm{a}, \mathrm{b}}$, Olivier Cuvillier ${ }^{\mathrm{b}}$, \\ Bernard Malavauda, b, Xavier Game ${ }^{\mathrm{a}, \mathrm{d}}$
}

\begin{abstract}
Background: Multiple sclerosis (MS) is the most common disabling neurological disorder affecting young adults. Lower urinary tract dysfunction (LUTD) is common during the course of MS and is responsible for an organic impact on the upper urinary tract and for impaired quality of life. Experimental autoimmune encephalomyelitis (EAE), an animal model of MS, is characterized in mice by paralysis of the tail and hind limbs progressing to paraplegia, but urinary parameters and voiding behavior are not well understood. We aimed to study micturition behavior of both healthy and EAE mice to determine changes induced by EAE.
\end{abstract}

Methods: Bladder function study included micturition behavior and filling cystometry.

Results: EAE mice developed profound bladder dysfunction characterized by a decrease in urine volume per micturition (138.8 \pm 20 vs. $213 \pm 17.5 \mu \mathrm{L}, \mathrm{P}=0.018$ ), significantly more frequent postvoid residual urine $(30 \%$ vs. $61 \%, \mathrm{P}=0.0496)$, and increased postvoid residual volume $(260 \pm 15$ vs. $197.5 \pm 12 \mu \mathrm{L}, \mathrm{P}=0.045)$. Cystometric analysis showed significantly more frequent detrusor overactivity (69\% vs. $1 \%, \mathrm{P}<0.0001)$.

Conclusions: Our study, characterizing bladder dysfunction in EAE mice by clinical and cystometric examination, showed that dysfunction was similar to neurological bladder disorders found in human multiple sclerosis and makes this model promising to assess new compounds.

Keywords: Multiple sclerosis; Experimental autoimmune encephalo-

Manuscript accepted for publication February 01, 2016

aDepartment of Urology, Renal Transplantation and Andrology, Rangueil University Hospital, Toulouse, France

bIPBS UMR5089 CNRS, Route de Narbonne, Toulouse, France

'Department of Pediatric Internal Surgery, Children's Hospital, Toulouse, France

dINSERM U1048, I2MC, Rangueil University Hospital, Toulouse, France ${ }^{e}$ Corresponding Author: Lucie Even, Department of Urology, Renal Transplantation and Andrology, Rangueil University Hospital, Toulouse, France. Email: even.1@chu-toulouse.fr

doi: http://dx.doi.org/10.14740/wjnu245w myelitis; Lower urinary tract dysfunction; Neurogenic bladder; Overactive bladder

\section{Introduction}

Multiple sclerosis (MS), a chronic demyelinating inflammatory disease, is the most common progressive neurological disease in the young adult, with marked female predominance (sex ratio 2:1) [1]. The prevalence of lower urinary tract dysfunction (LUTD) (30-96\%) increases with the duration of the disease. Dysfunction develops during the first 10 years of MS, but no link has been found between type of LUTD and duration of the course or form of the disease [2].

LUTD takes many forms. The clinical symptoms are dominated by filling dysfunction: clinical overactive bladder syndrome, or urgenturia and pollakiuria with or without urge incontinence. Voiding disturbances may also be present (obstructive symptoms such as dysuria and acute or chronic urinary retention) which may be associated with filling dysfunction. These clinical features are not related to urodynamic pattern and do not indicate the severity of urological impairment [3]. Urodynamic and morphological investigations together with laboratory tests are indispensable to characterize upper and lower urinary tract involvement. Detrusor overactivity is the most common abnormality (34-99\% of cases), while detrusor underactivity is observed in $5-37 \%$ of cases. Detrusor-sphincter dyssynergia is present in $6-82 \%$ of cases and may be associated with either over- or underactivity of the detrusor $[4,5]$. Urodynamic abnormalities change over time, whatever the form of MS [6]. LUTD leads to major impairment of quality of life and has a marked impact on renal function prognosis [7]. It requires specialized management [8].

Experimental autoimmune encephalomyelitis (EAE), a cell-mediated autoimmune disease, is one of the animal models of MS described by Olitsky and Yager in 1949 [9]. Only a few studies have previously addressed, and then only partially, clinical urinary symptomatology and the urodynamic pattern of the murine model of EAE [10-12]. However, the existence of a murine model of MS with clinical and cystometric functional urinary impairment that is comparable with the LUTD found in humans would be useful in the investigation of the 


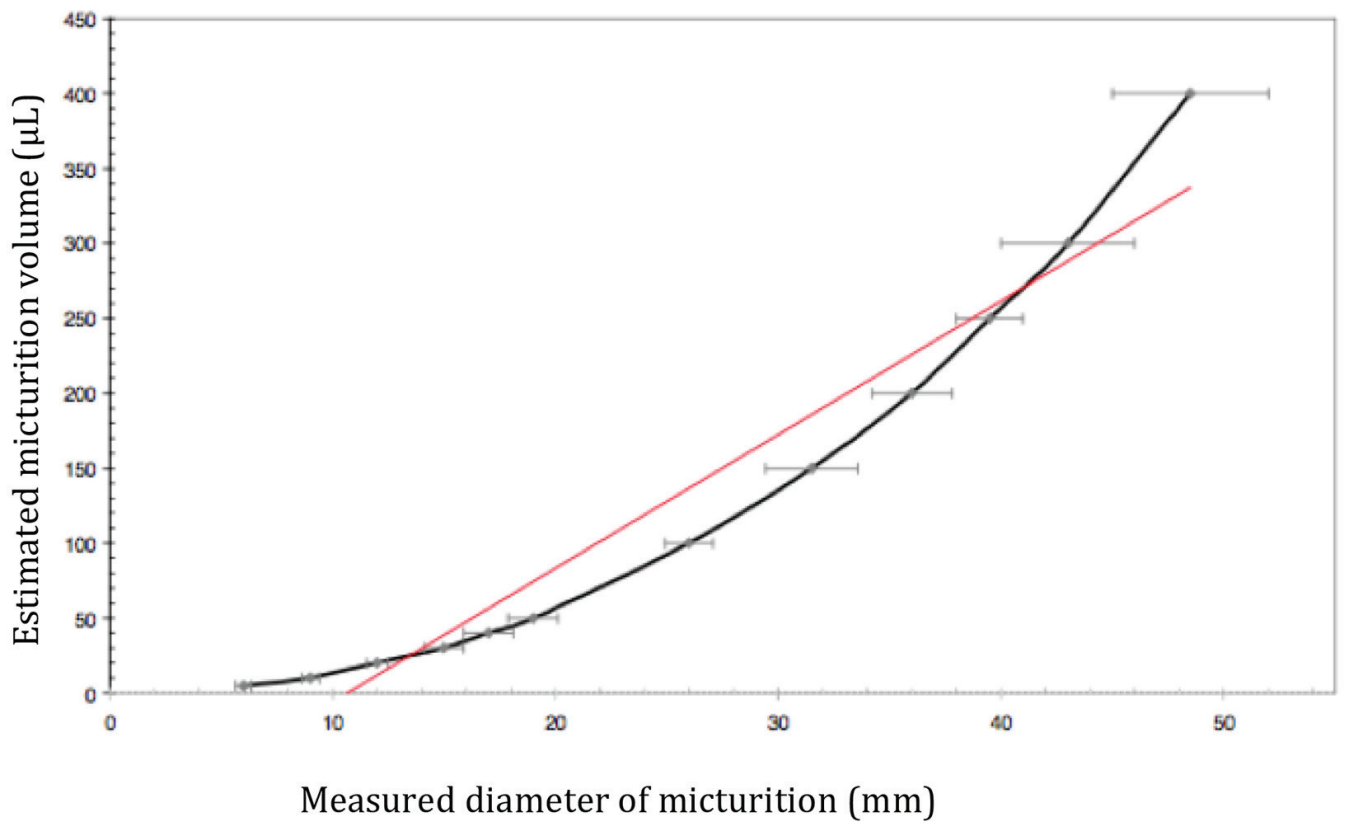

Figure 1. Curve of diameter/micturition volume. Calibration of micturition volume $(\mu \mathrm{L})$ correlated with diameter of micturition, measured from wet circle on absorbent paper $(\mathrm{mm})$ (mean \pm standard deviation). Red line: regression curve.

origin of these disorders and the development of appropriate treatments. The symptomatic treatments for LUTD that are currently prescribed are in fact not fully effective and also have major adverse effects, while the disease-modifying treatments of MS, immunomodulatory and immunosuppressive agents, have no demonstrated efficacy in LUTD as no study has yet been carried out.

The aim of this study was to determine, through functional and urodynamic study, whether or not EAE mice presented LUTD compared with a group of healthy mice.

\section{Materials and Methods}

\section{Experimental animal study}

Female C57/BL6 mice (Laboratoire Janvier, Le Genest St Isle, France) aged 11 weeks were housed in an animal facility in accordance with current recommendations at a temperature of 22 ${ }^{\circ} \mathrm{C}$ and a $12 \backslash \mathrm{h}$ light-dark cycle. The experiments were begun after 1 week of acclimation. The experimental protocol was submitted to the local ethics committee and validated under the number 13/5089/C/08.

\section{Induction and development of EAE}

The disease was induced under general anesthesia using 2\% isoflurane gas mixture (Baxter, Maurepas, France) and oxygen at a flow rate of $200-300 \mathrm{~mL} / \mathrm{min}$. Induction was carried out in the cages and anesthesia was maintained with a mask during handling.
The kits used for EAE induction were Hooke $\mathrm{Kit}^{\mathrm{TM}}$ $\mathrm{MOG}_{35-55} / \mathrm{CFA}$ Emulsion PTX (Hooke Laboratories, Lawrence, MA, USA). After the kit had been prepared according to the manufacturer's instructions, each mouse was given two injections of myelin oligodendrocyte glycoprotein (MOG) emulsion at the base of the neck and the tail, followed by intraperitoneal injection of the pertussis toxin preparation at day 0 and day 1 of induction. EAE was induced by a single researcher in similar environmental conditions in order to minimize bias in disease development.

As EAE causes weight loss and progressive caudocranial neurological signs, each mouse was weighed on the day of immunization, on day 4, day 7 and then daily. Tail atony and hind limb weakness during gait were also evaluated daily. Disease stage was scored according to Elloso et al from stage 0 (no overt sign of disease) to 6 (moribund) [13].

\section{Investigation of LUTD}

\section{Micturition diary}

The mice were placed in individual metabolic cages (Marty Technologie, Marcilly sur Eure, France) 12 h before starting the micturition diary, with food and water ad libitum for acclimation. Urine was collected on absorbent paper (Canson ${ }^{\circledR}$, Annonay, France) for $8 \mathrm{~h}$, followed by manual compression of the lower abdomen (Crede maneuver) for collection of postvoid residual urine (PVR). Unlike previously described protocols $[14,15]$, urine output was not quantified by weighing, but the time of each micturition and the diameter of the wet circle formed on the absorbent paper were recorded: this diameter 
Table 1. Results of Clinical and Urodynamic Investigations in Healthy and EAE Mice

\begin{tabular}{|c|c|c|c|}
\hline & Healthy mice & EAE mice & $\mathbf{P}$ \\
\hline $\operatorname{Mice}(\mathrm{n})$ & 20 & 36 & NS \\
\hline Weight at time of clinical and cystometric investigation (g) & $20.58 \pm 0.3$ & $16.89 \pm 0.24$ & 0.0001 \\
\hline \multicolumn{4}{|l|}{ Micturition diary variables } \\
\hline 8-h micturitions, (n) & $2.1 \pm 0.3$ & $2.6 \pm 0.2$ & NS \\
\hline Total 8-h urine output $(\mu \mathrm{L})$ & $623 \pm 90$ & $601 \pm 0.2$ & NS \\
\hline Mean urine volume per micturition $(\mu \mathrm{L})$ & $213 \pm 17.5$ & $138.8 \pm 20$ & 0.018 \\
\hline Persistence of PVR, \% (n) & $30(6 / 20)$ & $61(22 / 36)$ & 0.049 \\
\hline PVR volume $(\mu \mathrm{L})$ & $197.5 \pm 12$ & $260 \pm 15$ & 0.045 \\
\hline \multicolumn{4}{|l|}{ Cystometric variables } \\
\hline Detrusor overactivity, \% (n) & $10(2)$ & $69(25)$ & $<0.0001$ \\
\hline Area under the curve & $1,632 \pm 176$ & $2,475 \pm 24$ & NS \\
\hline Maximum bladder pressure $(\mathrm{mm} \mathrm{Hg} / \mu \mathrm{L})$ & $45.7 \pm 3$ & $46.3 \pm 3$ & NS \\
\hline
\end{tabular}

n: number in each group; \%: percentage; PVR: postvoid residual urine ; NS: non-significant.

was correlated with urine output (Fig. 1). Normal bladder capacity of healthy mice was estimated at $300-400 \mu \mathrm{L}$ and PVR was considered significant when bladder residual volume was more than $120 \mu \mathrm{L}$.

The variables analyzed were number of micturitions per $8 \mathrm{~h}$, mean urine volume per micturition, 8 -h urine output and PVR volume.

\section{Cystometric methods}

Cystometry was performed $24 \mathrm{~h}$ after the micturition diary. The general anesthesia was induced and maintained as previously described and mice were placed in a supine position. The bladder was catheterized using a transurethral approach with cathlon 22 gauge (Becton Dickinson ${ }^{\circledR}$, Madrid, Spain) on a flexible $0.46 \mathrm{~mm}$ guide (22 gauge pediatric central venous catheter guide $\left(\right.$ Arrow $^{\circledR}$, Teleflex, Le Faget, France)). The proximal extremity of the catheter was connected to an electric syringe pump (Pilote $C^{\circledR}$, Fresenius Vial Medical, Bad Homburg, Germany) to dilate the bladder with physiological saline at room temperature and at a constant rate $(3 \mathrm{~mL} / \mathrm{h}$ or $50 \mu \mathrm{L} /$ $\min )$.

The catheter was prolonged by a pressure transducer (Biopac System $^{\circledR}$, Paris, France) and connected to a Biopac MP 35 data acquisition and analysis system $\left(\right.$ Cerom $^{\circledR}$, Paris, France). The variables studied during bladder filling were presence or absence of detrusor overactivity, maximum bladder pressure (expressed in $\mathrm{mm} \mathrm{Hg}$ ) and the area under the curve between 50 and $250 \mu \mathrm{L}$ of filling, which reflects bladder compliance.

\section{Experimental conditions}

Firstly, lower urinary tract function was evaluated in 20 healthy female C57/BL6 mice by an 8-h micturition diary and cystometry. Secondly and under similar conditions, functional and urodynamic study of lower urinary tract function was carried out in 36 female C57/BL6 mice with EAE, with at least clinical stage 2 disease.

\section{Statistical analysis}

Statistical and graphic analysis was carried out using GraphPad Prism ${ }^{R}$ Version 5.0a software (GraphPad Software, Inc., La Jolla, CA, USA). Quantitative results are expressed as mean $\pm \mathrm{SD}$. Quantitative variables were compared using the Student's $t$-test. Qualitative variables and proportions were compared with the Chi-square test. A P value $<0.05$ was considered as statistically significant. Results were compared between the group of healthy mice and the group of EAE mice.

\section{Results}

The results of the clinical and urodynamic investigations are presented in Table 1.

\section{Disease induction rate}

Of the 40 mice in which EAE was induced, 36 developed the disease. Clinical stage 2 was reached between 13 and 16 days after induction. Median EAE stage when lower urinary tract function tests were carried out was $3.5(2-4)$.

\section{Weight changes}

The mean weight of the healthy mice at the time of functional and urodynamic testing was $20.58 \pm 0.13 \mathrm{~g}$. The mean initial weight of the mice before induction of EAE was $19.93 \pm 1.1 \mathrm{~g}$. At clinical stage 2 of the disease, before bladder function test- 


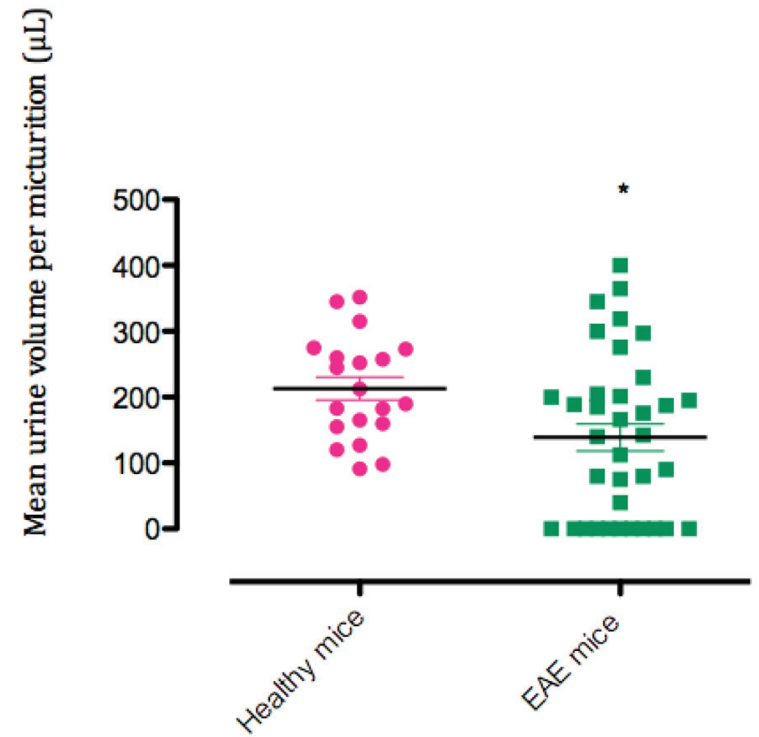

Figure 2. Mean urine volume per micturition. ${ }^{*} \mathrm{P}<0.05$

ing, the animals' weight showed a significant decrease with a mean weight of $16.89 \pm 0.24 \mathrm{~g}(\mathrm{P}<0.0001)$. The mean weights of healthy and EAE mice differed significantly at the time of testing $(20.58 \pm 0.13 \mathrm{~g}$ vs. $16.89 \pm 0.24 \mathrm{~g}$; $\mathrm{P}<0.0001)$.

\section{Micturition diary}

The number of micturitions per $8 \mathrm{~h}$ of EAE mice did not significantly differ from that of healthy mice $(2.1 \pm 0.3$ vs. 2.6 $\pm 0.2 ; \mathrm{P}=0.34)$. Total 8 -h urine output of EAE mice did not significantly differ from that of the healthy mice (623 \pm 90 vs. $601 \pm 46 \mu \mathrm{L} ; \mathrm{P}=0.8)$. Mean urine volume per micturition was

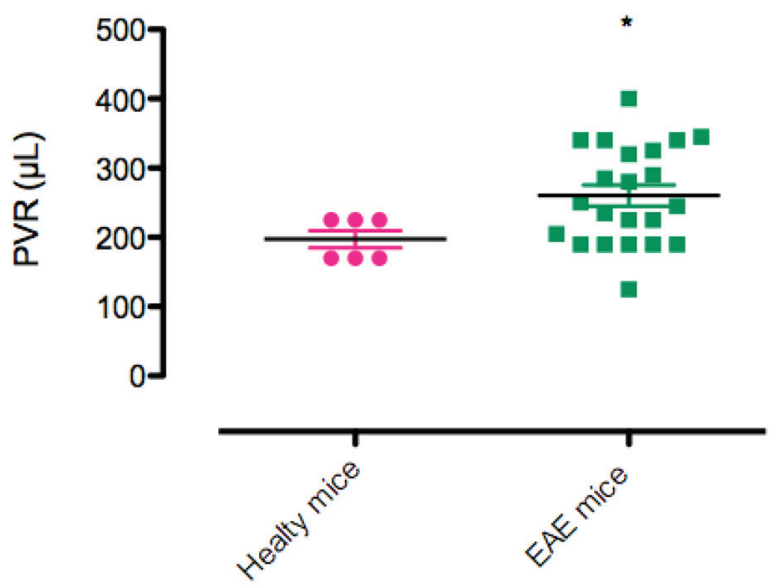

Figure 4. Postvoid residual urine (PVR) volume after $8 \mathrm{~h}(\mu \mathrm{L})$ in healthy mice and EAE mice. ${ }^{*} \mathrm{P}<0.05$.

significantly lower in EAE mice than in healthy mice $(138.8 \pm$ 20 vs. $213 \pm 17.5 \mu \mathrm{L}$; $\mathrm{P}=0.018$; Fig. 2).

Six of the 20 healthy mice $(30 \%)$ and 22 of the 36 EAE mice $(61 \%)$ had PVR. Persisting PVR was significantly more frequent in EAE mice than in healthy mice $(P=0.0496)$ (Fig. $3)$. In mice with PVR, mean volume was significantly higher in EAE mice than in healthy mice $(260 \pm 15$ vs. $197.5 \pm 12 \mu \mathrm{L}$; $\mathrm{P}=0.045$ ) (Fig. 4).

Of the EAE mice, $10(27.7 \%)$ failed to urinate during the 8 -h urine collection. At the end of the 8-h period, PVR was found in six mice while the four others had an empty bladder. In all these mice, disease stage was at least 3.

The clinical disease stage and the variables of the micturition diary were related to a significantly lower number of 8 -h micturitions $(\mathrm{P}=0.0491)$, decreased urine volume per micturition $(\mathrm{P}=0.0009)$ and urine output $(\mathrm{P}=0.0298)$, in parallel with

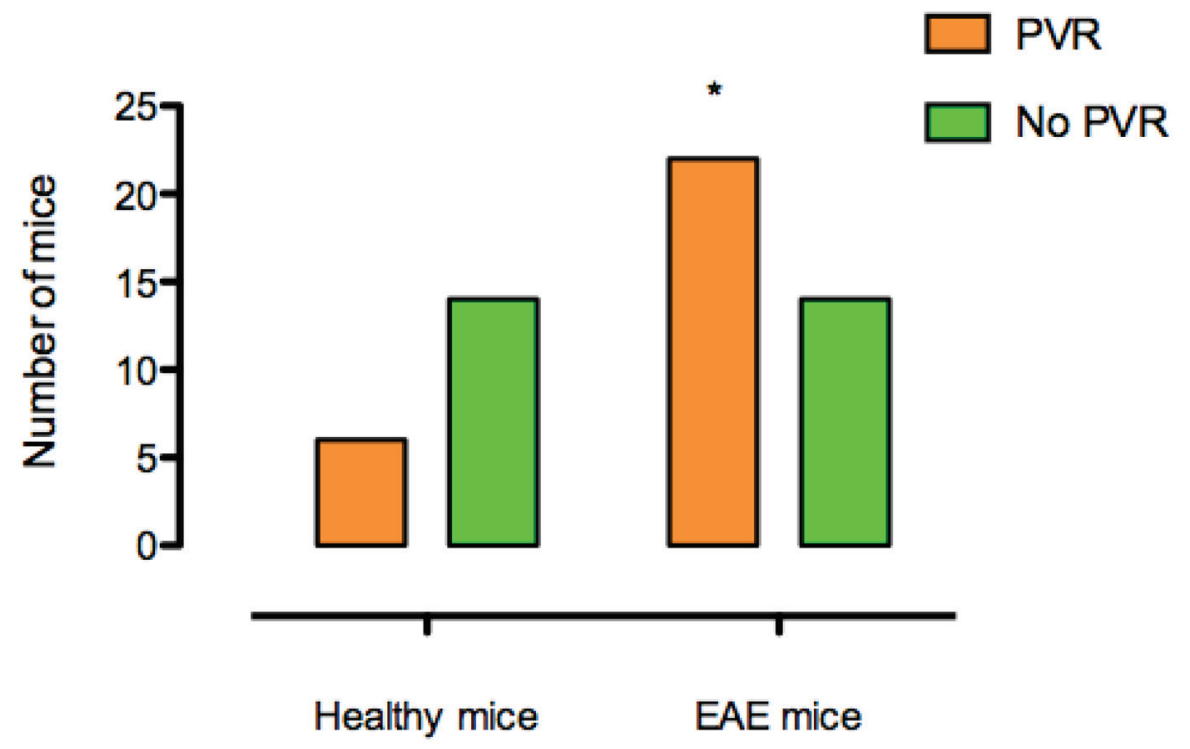

Figure 3. Persistence of postvoid residual urine (PVR) in healthy and EAE mice. ${ }^{*} \mathrm{P}<0.05$. 


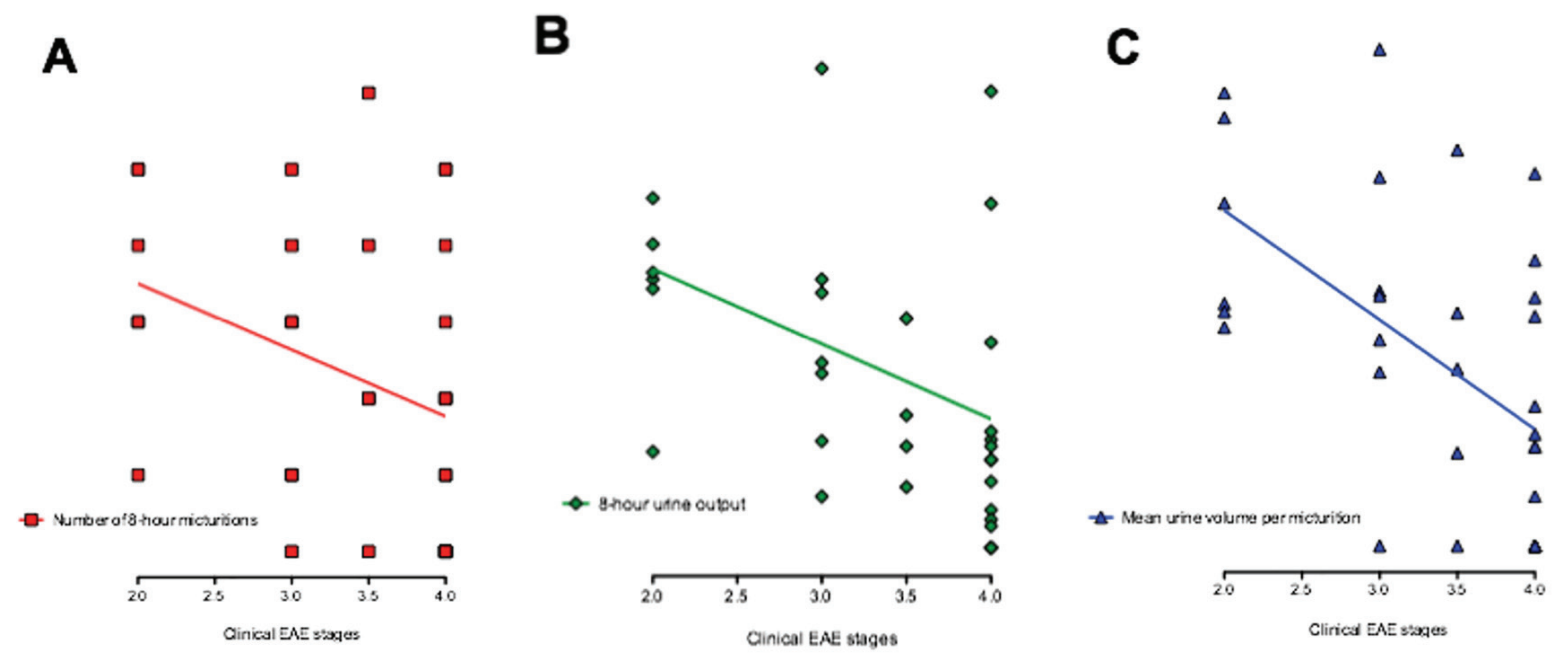

Figure 5. Correlation between clinical EAE stages and micturition diary variables. (A) Correlation between clinical EAE stages and number of 8-h micturitions. ${ }^{*} P=0.049$. (B) Correlation between clinical EAE stages and 8-h urine output. ${ }^{*} P=0.029$. (C) Correlation between clinical EAE stages and mean urine volume per micturition. ${ }^{* \star} \mathrm{P}=0.009$.

more advanced disease stage (Fig. 5). There was no correlation between PVR volume and clinical EAE stage.

\section{Urodynamic findings}

Abnormal voiding pattern with detrusor overactivity was significantly more frequent among EAE mice $(25$ of $36,69 \%)$ than among healthy mice (two of 20,10\%) (P<0.0001) (Fig. 6 ). The mean area under the curve was $1,632 \pm 176$ in healthy mice. It was significantly higher in EAE mice, at 2,475 \pm 24 $(\mathrm{P}=0.017)$. Bladder pressure did not differ between the two groups: $47.5 \pm 3 \mathrm{~mm} \mathrm{Hg} / \mu \mathrm{L}$ in healthy mice and $46.3 \pm 3 \mathrm{~mm}$ $\mathrm{Hg} / \mu \mathrm{L}$ in EAE mice $(\mathrm{P}=0.8)$. No link was found between clinical disease stage and the development of detrusor overactivity.

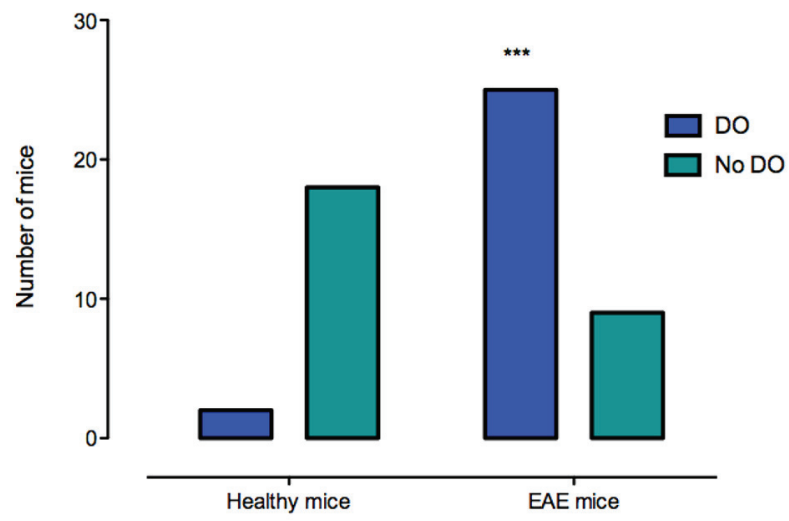

Figure 6. Detrusor overactivity in healthy and EAE mice. ${ }^{* *} \mathrm{P}<0.0001$. DO: detrusor overactivity.

\section{Discussion}

Compared with healthy mice, the EAE mice with EAE induced by $\mathrm{MOG}_{35-55}$ had clinical LUTD with urine retention, associated with detrusor overactivity in parallel with motor deficiency.

Induction of EAE had a $90 \%$ success rate and the progression of the disease was similar to the data of the literature [16]. Berard et al have described two forms of expression of EAE induced by $\mathrm{MOG}_{35-55}$ in C57/BL6 mice, depending on the titration: a chronic progressive form and a relapsing-remitting form [17]. For our study, rather than the relapsing-remitting form, we preferred the progressive form, which offers greater stability for carrying out functional investigations. With regard to choice of gender, female mice were naturally chosen for epidemiological reasons (the female population is more severely affected by MS (sex ratio: 2:1) [1]) and for technical reasons (easier catheterization in female mice). When study of LUTD was carried out, the disease was at least stage 2 , in accordance with the data of the literature [10-12].

Functional bladder study demonstrated that a urinary retention pattern predominates in EAE mice: decreased number of micturitions per $8 \mathrm{~h}$ and lower urine volume per micturition, with no difference in total 8-h urine output and increased PVR volume. Altuntas et al reported that female SWXJ mice with EAE had LUTD with an increased number of micturitions per $24 \mathrm{~h}$ and lower urine volume per micturition. However, the animal model of these authors was different and EAE was induced by means of PLP ${ }_{139-151}$. In addition, as PVR was not measured and urodynamic studies were not done, the mechanism could not be identified and the increased micturitions could be related to leakage due to overflow incontinence [10].

We identified a link between clinical disease stages and micturition diary findings: the number of micturitions per 8 
$\mathrm{h}$, urine output volume per micturition and 8-h urine output decreased as the disease progressed. Two possible mechanisms may be proposed: on the one hand, increasing motor disability leading to decreased fluid intake, and on the other hand, the progression of central demyelination responsible for impaired bladder and sphincter control.

Concerning urodynamics, we report the development of detrusor overactivity with decreased bladder pressure in EAE mice. These results confirm the finding recently reported by Franken et al in the same model [18]. Mizusawa et al described a strong predominance of detrusor areflexia in the cystometric patterns of EAE Lewis rats, although detrusor dysfunction only appeared during a short period of EAE progression and it was reversible [11]. However, in these animals, the disease had been induced using an MBP peptide. Both urodynamic investigations were carried out using a different protocol from ours, which required placement of an indwelling suprapubic bladder catheter for continuous recording of micturition cycles. Bladder puncture, as well as being invasive and non-physiological, could be a source of artifacts. Carrying out cystometry under general anesthesia and by urethral catheterization appears less invasive and more physiological than suprapubic catheterization. We did not repeat the urodynamic investigations in order to limit as much as possible the iatrogenic effect of bladder dilation.

Whereas we found a link between clinical EAE stages and micturition diary findings, we found no correlation between clinical stages and urodynamic findings. Some studies have found a link between neurological disturbances and cystometric patterns, but the animal model (rat) and method of induction were different, and the dysfunction identified was detrusor areflexia. In female EAE Lewis rats, Vignes et al reported two different patterns of bladder dysfunction, detrusor areflexia and hyperactivity, which were present in equal proportions at stages 2 - 4 of the disease [12]. Franken et al reported correlation between higher clinical score and urodynamic parameters. They showed an increased micturition frequency, a decreased bladder capacity, in maximum pressure and in voiding amplitude in mice with higher clinical score and concluded to correlation between bladder dysfunction and clinical status. However, we could consider that these results reflect a decrease in urethral resistance and not a detrusor dysfunction [18].

Our study differs from previous studies by the animal model and the diversity of clinical stages at the time of urodynamic investigation. The method of EAE induction is also an important variable that needs to be taken into account.

A limitation of our study is that urethral resistance was not investigated. The association of PVR and detrusor overactivity in fact suggests an outlet obstruction that can be investigated by measurement of leak point pressure, which reflects urethral resistance [14]. Another limitation of the study is the absence of morphological and histological examination of the spinal cord, which would make it possible to seek a link between the presence and location of demyelinating lesions and clinical and urodynamic LUTD. Gross and histological examination of the bladders of EAE mice would also be informative.

The animal model of C57/BL6 EAE mice is reproducible and its clinical and urodynamic pattern is easily observed. Disease progression and the urinary retention and overactive bladder pattern are comparable to the clinical profiles of MS patients. The animal model is therefore an interesting one for physiological study of bladder dysfunction in MS, and it is also a model of neurogenic bladder that could be used in preclinical evaluation of candidate drugs.

\section{Conclusion}

C57/BL6 mice with EAE, a murine model of MS, presented with LUTD with increased postvoid residual volume and detrusor overactivity in addition to the motor dysfunction already identified in this disease. This appears to be a promising model for study not only of the origins of LUTD, but also for the development and evaluation of appropriate treatment strategies for neurogenic bladder and sphincter disorders.

\section{Acknowledgement}

The authors thank the Association Francaise d'Urologie for financial support.

\section{Conflict of Interest}

Authors declare no conflict of interest related to this manuscript.

\section{References}

1. Brassat D. [Pathophysiology of multiple sclerosis]. Presse Med. 2010;39(3):341-348.

2. de Seze M, Game X. [Multiple sclerosis and pelviperineology: Urinary and sexual dysfunctions and pregnancy]. Prog Urol. 2014;24(8):483-494.

3. Gallien P, Robineau S, Nicolas B, Le Bot MP, Brissot $\mathrm{R}$, Verin M. Vesicourethral dysfunction and urodynamic findings in multiple sclerosis: a study of 149 cases. Arch Phys Med Rehabil. 1998;79(3):255-257.

4. Bart S, De Seze M, Chartier-Kastler E, Ruffion A. [Lower urinary tract dysfunction and multiple sclerosis]. Prog Urol. 2007;17(3):358-364.

5. Amarenco G, Kerdraon J, Denys P. [Bladder and sphincter disorders in multiple sclerosis. Clinical, urodynamic and neurophysiological study of 225 cases]. Rev Neurol (Paris). 1995;151(12):722-730.

6. Ciancio SJ, Mutchnik SE, Rivera VM, Boone TB. Urodynamic pattern changes in multiple sclerosis. Urology. 2001;57(2):239-245.

7. Castel-Lacanal E, Game X, Clanet M, Gasq D, De Boissezon X, Guillotreau J, Bourg V, et al. Urinary complications and risk factors in symptomatic multiple sclerosis patients. Study of a cohort of 328 patients. Neurourol Urodyn. 2015;34(1):32-36.

8. de Seze M, Ruffion A, Denys P, Joseph PA, Perrouin-Verbe $\mathrm{B}$. The neurogenic bladder in multiple sclerosis: re- 
view of the literature and proposal of management guidelines. Mult Scler. 2007;13(7):915-928.

9. Olitsky PK, Yager RH. Experimental disseminated encephalomyelitis in white mice. J Exp Med. 1949;90(3):213-224.

10. Altuntas CZ, Daneshgari F, Liu G, Fabiyi A, Kavran M, Johnson JM, Gulen MF, et al. Bladder dysfunction in mice with experimental autoimmune encephalomyelitis. J Neuroimmunol. 2008;203(1):58-63.

11. Mizusawa $\mathrm{H}$, Igawa $\mathrm{Y}$, Nishizawa $\mathrm{O}$, Ichikawa $\mathrm{M}$, Ito $\mathrm{M}$, Andersson KE. A rat model for investigation of bladder dysfunction associated with demyelinating disease resembling multiple sclerosis. Neurourol Urodyn. 2000;19(6):689-699.

12. Vignes JR, Deloire MS, Petry KG, Nagy F. Characterization and restoration of altered inhibitory and excitatory control of micturition reflex in experimental autoimmune encephalomyelitis in rats. J Physiol. 2007;578(Pt 2):439450 .

13. Elloso MM, Phiel K, Henderson RA, Harris HA, Adelman SJ. Suppression of experimental autoimmune encephalomyelitis using estrogen receptor-selective ligands. J Endocrinol. 2005;185(2):243-252.

14. Game X, Allard J, Escourrou G, Gourdy P, Tack I,
Rischmann P, Arnal JF, et al. Estradiol increases urethral tone through the local inhibition of neuronal nitric oxide synthase expression. Am J Physiol Regul Integr Comp Physiol. 2008;294(3):R851-857.

15. Burnett AL, Calvin DC, Chamness SL, Liu JX, Nelson RJ, Klein SL, Dawson VL, et al. Urinary bladder-urethral sphincter dysfunction in mice with targeted disruption of neuronal nitric oxide synthase models idiopathic voiding disorders in humans. Nat Med. 1997;3(5):571-574.

16. Budde MD, Kim JH, Liang HF, Russell JH, Cross AH, Song SK. Axonal injury detected by in vivo diffusion tensor imaging correlates with neurological disability in a mouse model of multiple sclerosis. NMR Biomed. 2008;21(6):589-597.

17. Berard JL, Wolak K, Fournier S, David S. Characterization of relapsing-remitting and chronic forms of experimental autoimmune encephalomyelitis in C57BL/6 mice. Glia. 2010;58(4):434-445.

18. Franken J, Gevaert T, Uvin P, Wauterickx K, Boeve AC, Rietjens R, Boudes M, et al. Urodynamic changes in mice with experimental autoimmune encephalomyelitis correlate with neurological impairment. Neurourol Urodyn. 2015. 